\title{
Neutral lipid fatty acid analysis is a sensitive marker for quantitative estimation of arbuscular mycorrhizal fungi in agricultural soil with crops of different mycotrophy
}

Mauritz Vestberg ${ }^{1}$, Ansa Palojärvi², Timo Pitkänen ${ }^{3}$, Saara Kaipainen², Elina Puolakka ${ }^{1}$ and Marjo Keskitalo

${ }^{1}$ MTT Agrifood Research Finland, Plant Production Research, FI-41330 Vihtavuori, Finland

${ }^{2}$ MTT Agrifood Research Finland, Plant Production Research, Fl-31600 Jokioinen, Finland

${ }^{3}$ MTT Agrifood Research Finland, Biotechnology and Food Research, FI-31600 Jokioinen, Finland e-mail: mauritz.vestberg@mtt.fi

\begin{abstract}
The impact of host mycotrophy on arbuscular mycorrhizal fungal (AMF) markers was studied in a temperate agricultural soil cropped with mycorrhizal barley, flax, reed canary-grass, timothy, caraway and quinoa and non-mycorrhizal buckwheat, dyer's woad, nettle and false flax. The percentage of AMF root colonization, the numbers of infective propagules by the Most Probable Number (MPN) method, and the amounts of signature Phospholipid Fatty Acid (PLFA) 16:1 $\omega 5$ and Neutral Lipid Fatty Acid (NLFA) 16:1 $\omega 5$ were measured as AMF markers. Crop had a significant impact on MPN levels of AMF, on NLFA 16:1w5 levels in bulk and rhizosphere soil and on PLFA 16:1 $\omega 5$ levels in rhizosphere soil. Reed canary-grass induced the highest levels of AMF markers. Mycorrhizal markers were at low levels in all non-mycorrhizal crops. NLFA 16:1 $\omega 5$ and the ratio of NLFA to PLFA 16:1 $\omega 5$ from bulk soil are adequate methods as indicators of AMF biomass in soil.
\end{abstract}

Key words: Arbuscular mycorrhizal fungi, AMF quantification, PLFA, NLFA, field crops

\section{Introduction}

Arbuscular mycorrhizal (AM) symbiosis is found in the large majority of terrestrial plants (Newman and Reddell 1987) and has been estimated to occur in almost a quarter of a million plant species (Gadkar et al. 2001). AM symbiosis plays an important role in natural ecosystems as well as in agroecosystems. The AM fungi (AMF) are multifunctional, improving plant growth through increased uptake of available soil phosphorus (P) and other non-labile essential minerals (Smith and Read 1997). Other beneficial impacts of AMF are for example alleviation of plant stress caused by abiotic (Evelin et al. 2009) and biotic (Pozo et al. 2010) factors and stabilization of soil aggregates (Rillig 2004) by producing the glycoprotein glomalin (Wright and Upadhyaya 1996).

Common agricultural practices, such as fertilization, frequent soil disturbance and monoculture affect indigenous AMF negatively (Douds and Millner 1999). High-input conventional cropping systems have been shown to reduce abundance and diversity of AMF communities more than low-input systems (Oehl et al. 2004). In crop rotations, the amount and function of indigenous AMF is also affected by the incorporation of previous crops with varying degree of mycotrophy. Non-host crops and long fallow periods may reduce AMF quantitatively and qualitatively (Harinikumar and Bagyaraj 1988, Troeh and Loynachan 2003). The growth and yield of a crop may be affected by the previous crop (Karlen et al. 1994), an important factor to consider when designing crop rotations. In a Japanese study, the mycotrophy (non-mycorrhizal mustard 


\section{AGRICULTURAL AND FOOD SCIENCE}

M. Vestberg et al. (2012) 21: 12-27

vs. mycorrhizal sunflower) of the preceding crop was shown to be the most important factor influencing growth and yield of successive maize (Karasawa et al. 2001).

AMF can be estimated quantitatively in soil by various methods, all of which have their advantages and disadvantages. Following staining, AM fungal hyphae can be counted visually and their length estimated under the microscope and subjectively differentiated from the hyphae of other fungi, but this method includes both living and dead hyphae (Olsson 1999). AMF spores can be extracted from soil volume by decanting and sieving (Gerdemannn and Nicholson 1963), but usually also in this case no differentiation between living and dead spores is done. A great bias when counting spores from soil is the fact that many AMF do not produce spores readily and that there is a great variation in spore production between different species.

The most probable number method (MPN) for estimating numbers of infective microbiological microorganisms has been adapted for AMF research (Porter 1979). This method takes into account all types of infective AM fungal propagules including hyphae, colonized roots and spores. The MPN method has for example been used for comparing mycorrhizal propagule numbers under certain crops (An et al. 1993), in contrasting cropping systems (Troech and Loynachan 2003), in a studies of AMF in contaminated soil (Carvalho et al. 2001), in surveys of AMF in geographically larger areas (Wang et al. 2008) or as a measure of infectivity of AMF inocula (McGee et al. 1999).

There has been some debate about the scientific value of the MPN assay. The assay does provide useful data of the infectivity of AMF, but the estimates are also very dependent on the experimental conditions used. From this point of view, comparisons of MPN levels of studies done in highly different ecological situations can be seen as only indicative (Wang et al. 2008), while MPN counts from comparative studies in field experiments can be regarded as useful. Wilson and Trinick (1982) listed several factors having a high impact on the result in MPN studies, including host plant, temperature, time of harvest, pot size, soil (whether dry of moist), nutrient status of diluent, etc.

All structures of AM fungi, including hyphae, spores and vesicles, are rich in lipids. Quantitative analyses of lipids have therefore been used for studying AMF in soil. The two most important types of lipids found in organisms are phospholipids (membrane constituents) and neutral lipids (energy storage in eukaryotes). Both these types of lipids contain fatty acids connected to a glycerol backbone (Olsson 1999). The fatty acid composition of lipids in AM fungi differs from that of other organisms. In most AM fungi a large proportion of the total fatty acids is found as $16: 1 \omega 5$ and 18:1 1 7 (Johansen et al. 1996; Olsson et al. 1999) and as polyunsaturated 20-carbon fatty acids (Olsson and Johansen 2000). The numbers of AMF spores formed in soil has been found to correlate most closely with the neutral lipid fatty acid (NLFA) 16:1 $\omega 5$ content of soil, whereas the hyphal length in soil correlated most closely with the phospholipid fatty acid

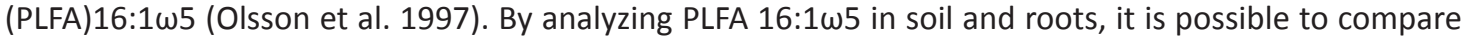
the biomass of external and internal AM fungal mycelium (Olsson et al. 1999). However, in such analyses there will always be a background level of PLFA 16:1 $\omega 5$ that originates mainly from bacteria or from non AMF fungi (Olssonet al 1997). The level of this background PLFA 16:1 $\omega 5$ can be considerable, accounting for $30-60 \%$ of the total PLFA 16:1 $\omega 5$ (Olsson et al. 1999). NLFA 16:1 $\omega 5$ is more sensitive than PLFA 16:1 $\omega 5$ as an indicator of AM mycelia in soil since the ratio between NLFA and PLFA 16:1 $\omega 5$ is high in AM fungi (1-200), while it is low in bacteria (<1) (Olsson et al. 1997). Apart from being a tool for the estimation of AM fungal biomass in soil, phospholipid fatty acids can also be used for taxonomical analyses of AMF (Graham et al. 1995), for studying interactions between AMF and pathogens (Larsen et al. 1998) and for studying microbial communities in soil (Batten et al. 2008). 


\section{AGRICULTURAL AND FOOD SCIENCE}

M. Vestberg et al. (2012) 21: 12-27

At MTT Agrifood Research Finland, a 3-year study with nine special crops was carried out to investigate their effect on above and below ground biodiversity of the field. The main criteria for choosing an individual crop were their special nutrient usage characteristics, high biomass production above and/or below ground and flowering traits promoting field biodiversity (Hakala et al. 2009). An additional aspect was their economic potential as cash crop in the crop rotation. Several of the minor crops studied are known for various physiological traits, for example deep root systems and potential of removing excess nutrients from soil, which potentially affect their suitability in crop rotations (Hakala et al. 2009). Greater variety of crops in the rotation systems and increased cultivation of perennial or autumn sown crops can act as a buffer against changing environmental conditions (Hakala et al. 2009). Studying the impacts of these crops on soil microorganisms, in particular the AMF, is a novel rationale.

The main aim of the study was to find out the impact of some special crops on AMF infectivity in soil in relation to the commonly grown Finnish crop barley. We also aimed at comparing the feasibility of different methods for quantitative estimation of AMF in soil and rhizosphere. The methods used included estimation of AMF root colonization, the most probable numbers of AMF and levels of signature fatty acids PLFA 16:1 $\omega 5$ and NLFA 16:1 $\omega 5$. The total amount of PLFAs was used as an indicator for total microbial biomass and PLFA 18:2 as an indicator of saprophytic fungal biomass.

\section{Material and Methods}

\section{Experimental setup}

Ten crops were grown in a field experiment in a randomized block design with five replicates during the growing seasons 2004-2006. Three blocks were utilized in this study. The size of individual plots was $30 \mathrm{~m}^{2}$ $(3 \times 10 \mathrm{~m}$; width $\times$ length). The crops were the annual barley (Hordeum vulgare), buckwheat (Fagopyrum esculentum), flax (Linum usitatissimum), false flax (Camelina sativa) and quinoa (Chenopodium quinoa), and the perennial reed canary-grass (Phalaris arundinacea), timothy (Phleum pratense), nettle (Urtica dioica), caraway (Carum carvi) and dyer's woad (Isatis tinctoria). Five of the crops, i.e. barley, flax, reed canary-grass, timothy and caraway are known to be mycorrhizal (Harley and Harley 1987) while buckwheat (Harley and Harley 1987), dyer's woad (Pendleton and Smith 1983) and nettle (Vierheilig et al. 1996) are usually non-mycorrhizal. No information about the mycorrhizal status of false flax can be found but as a Brassicaceae-plant it is presumably non-mycorrhizal. The Chenopodiaceae species quinoa has been found slightly mycorrhizal following simazine treatment (Schwab et al. 1982), but was found non-mycorrhizal in another study (Urcelay et al. 2011).

The field was located in south-western Finland, at MTT Agrifood Research Finland $\left(60^{\circ} 49^{\prime} \mathrm{N}, 23^{\circ} 28^{\prime} \mathrm{E}\right)$. The experiment was established on a sandy clay. Initial soil properties (mean of ten measurements) were $\mathrm{pH}_{\mathrm{H} 2 \mathrm{O}}$ 6.2 , organic carbon $3.3 \%$, total nitrogen (N) $0.19 \%$, ammonium-acetate-extractable (Vuorinen and Mäkitie 1955) calcium (Ca) $2192 \mathrm{mg} \mathrm{kg}^{-1}$ soil, potassium (K) $166 \mathrm{mg} \mathrm{kg}^{-1}$ soil, magnesium (Mg) $200 \mathrm{mg} \mathrm{kg}^{-1}$ soil, and phosphorus (P) $9.5 \mathrm{mg} \mathrm{kg}^{-1}$ soil. Crops were sown, fertilized and harvested according to normal agricultural practise. None of the plots were ploughed in the previous autumn. As part of normal agricultural practise, the herbicides trifluralin was applied to false flax and bentazon with MCPA to barley and flax during the growing season in the year of sampling. Quinoa and false flax plots received pesticides alpha-cypermetrin and deltametrin, respectively. No fungicides were used. 


\section{AGRICULTURAL AND FOOD SCIENCE}

M. Vestberg et al. (2012) 21: 12-27

\section{Sampling and sample treatment}

Intact soil samples were dug up with a spade from one area (size $50 \mathrm{~cm} \times 100 \mathrm{~cm} \times 20 \mathrm{~cm}$; width x length $x$ depth) per plot in blocks 2, 3 and 4 after ripening or at the end of growing season of each crop during August and September 2005. Crops ripened in the following order: caraway, barley, false flax, buckwheat, dyer's woad, flax, timothy, nettle, reed canary-grass and quinoa. In the laboratory, roots were separated from the bulk soil by hand.

Rhizosphere soil sampling was carried out according to Schmalenberger and Tebbe (2003) with slight modifications. The roots were separated from the bulk soil by hand. A pooled bulk soil sample, approx. $200 \mathrm{~g}$ was stored in a freezer. About $4 \mathrm{~g}$ root material was transferred to sterile $50 \mathrm{ml}$ tubes. A total of 20 $\mathrm{ml}$ sterile saline $(0.85 \% \mathrm{NaCl}, \mathrm{w} / \mathrm{vol})$ was added to each tube and tubes were incubated for $30 \mathrm{~min}$ at $4{ }^{\circ} \mathrm{C}$ and $50 \mathrm{rpm}$ in an orbital shaker. Roots were removed from tubes and the rhizosphere soil samples were collected by centrifugation at $2100 * \mathrm{G}$ for $30 \mathrm{~min}$ at $4{ }^{\circ} \mathrm{C}$. The supernatants were discarded. Both bulk and rhizosphere soil samples were freeze-dried and stored at $-18^{\circ} \mathrm{C}$. For the estimation of the percentage of AMF colonization in roots, separate $1 \mathrm{~g}$ washed root samples were preserved in $50 \%$ ethanol and stored in the refrigerator $\left(+4^{\circ} \mathrm{C}\right)$ until further staining and microscopy.

\section{AMF root colonization}

To estimate AMF root colonization in field samples, representative triplicate root samples of $1 \mathrm{~g}$ fresh weight each were bleached in $10 \%$ potassium hydroxide $(\mathrm{KOH})$ overnight and acidified in $1 \%$ hydrocloric adic $(\mathrm{HCl})$ before staining at $90{ }^{\circ} \mathrm{C}$ for one hour with $0.01 \%$ methyl blue (Grace and Stribley 1991). Root colonization was estimated under a dissecting microscope on the following rating scale: $0,0-1,2-5,6-10,11-20$, 21-30,....91-100\%. Arbuscules, vesicles, and typical intraradical hyphae were counted as colonization.

\section{AMF markers in soil}

\section{Most probable number (MPN) assay}

The MPN assay was carried out in a greenhouse under natural light at MTT, Laukaa, between 4 July and 9 August, 2006. A mixture $(5: 1)$ of steam sterilized sand and moderately fertilized commercial peat B2 (Kekkilä Oyj, Finland) was used as diluent. Mixtures were made of field soil and the diluent in five successive fourfold dilutions from $4^{-2}$ to $4^{-6}$ as described by Sieverding (1991). The number of replicates was five and the size of individual pots (Polar cup, Finland) $227 \mathrm{ml}$. Two seeds of maize cv Arthur were sown in each pot. The pots were kept in a growth chamber with artificial light until emergence after which they were transferred to a green house and randomized within the five replicates. At this stage, each pot was put inside a larger intact container that had a $3 \mathrm{~cm}$ layer of sterile sand at the bottom. Water was applied into the larger container from where it was sucked into the smaller pot containing the maize seedling. No extra fertilizers were applied. At harvest, roots were cut from the centre of each pot. Absence or presence of AMF colonization was recorded after staining of roots with methyl blue (Grace and Stribley 1991). The MPN numbers for each soil sample were estimated according to Sieverding (1991) and Fisher and Yates Table VIII (1970). Results are expressed as the number of infective propagules per $100 \mathrm{~g}$ oven dry soil. 


\section{AGRICULTURAL AND FOOD SCIENCE}

M. Vestberg et al. (2012) 21: 12-27

\section{Fatty acid analyses}

PLFAs were analysed from soils of all crop species except dyer's woad according to Frostegård et al. (1993) and Stoeck et al. (2002) with slight modifications. Briefly, $3 \mathrm{~g}$ of freeze-dried bulk soil sample and about $2 \mathrm{~g}$ of freeze-dried rhizosphere soil sample were extracted with a chloroform-methanol-citrate -buffer mixture (1:2:0.8; "Bligh \& Dyer mixture"). The lipids were separated into neutral lipids, glycolipids and phospholipids in a silicic acid column (Varian Bond Elut SILICA SI $500 \mathrm{mg}$ ). The phospholipids and neutral lipids were subjected to mild alkaline methanolysis to recover fatty-acid methyl esters. Samples were analysed with a gas chromatograph with mass selective detector (GC-MS; Hewlett Packard 5890 series II gas chromatograph, Hewlett Packard 5971 series mass selective detector) equipped with a 50-m-long, non-polar, phenyl-methyl silicone capillary column (HP-5; $0.2 \mathrm{~mm}, 0.33 \mu \mathrm{m}$ ). Helium was used as carrier gas at a flow rate of $0.9 \mathrm{ml} \mathrm{min}^{-1}$. The temperature of the injector was $280{ }^{\circ} \mathrm{C}$. The time-temperature program for the oven was as follows: initial temperature $90^{\circ} \mathrm{C}$ for $2 \mathrm{~min}$, increase $30^{\circ} \mathrm{C} \mathrm{min} \mathrm{m}^{-1}$ until 160 o C, increase $3^{\circ} \mathrm{C} \mathrm{min}-1$ until $280^{\circ} \mathrm{C}$, final temperature $280^{\circ} \mathrm{C}$ for $10 \mathrm{~min}$. The identification and response factors of the different PLFA compounds were based on FAME standards (Sigma, Supelco, Nu-Chek-Prep, Larodan Fine Chemicals AB).

Signature fatty acids PLFA 16:1 $\omega 5$ and NLFA 16:1 $1 \omega 5$ were used as indicators of AM fungal biomass in soil (Olsson 1999). The total amount of PLFAs (PLFAtot) was used as an indicator of total microbial biomass and PLFA 18:2 as an indicator of saprophytic fungal biomass ( $\mathrm{nmol} \mathrm{g}^{-1}$ dry soil) in soil (Frostegård et al. 1993).

\section{Statistical methods}

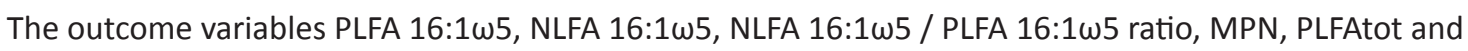
PLFA 18:2 were analysed according to the following statistical model for randomized block design:

$$
y_{i j}=\mu+c_{i}+b_{j}+\varepsilon_{i j}
$$

where $\mu$ is the constant, $c_{i}$ is the fixed crop effect for crop i, $b_{j}$ is the random block effect for block $j$ and $\varepsilon_{i j}$ is the random error term. The random variables $b_{j}$ and $\varepsilon_{i j}$ are assumed to be mutually independent and normally distributed with zero means and variances $\sigma_{b}{ }^{2}$ and $\sigma^{2}$, respectively. The samples from bulk soil and rhizosphere soil were analysed separately.

Appropriateness of the model was studied through residual analyses. Residuals were checked for normality by using box plots (Tukey 1977) and plotted against the fitted values. All outcome variables were log-transformed prior to statistical analysis. Comparisons between crop means were made by two-sided t-type tests. The models were fitted by using the residual maximum likelihood (REML) estimation method. The degrees of freedom were computed by the method described by Kenward and Roger (1997). The analyses were performed using the MIXED procedure (Littell et al. 1996) in SAS/STAT software version 9.2 (SAS Institute Inc., Cary, NC, USA).

Comparisons between AMF markers were done by using correlation coefficient. Logarithm transformation of markers was used. The analyses were performed using the MIXED procedure (Littell et al. 1996) in SAS/STAT software and correlations were calculated using the CORR procedure in SAS/BASE software version 9.2 (SAS Institute Inc., Cary, NC, USA). These methods were used only in a descriptive manner because the sample size was small and the AMF markers were in different scales. The use of correlation coefficient in method comparison studies has problems (Altman and Bland 1983), so we do not make strong statements about correlations between AMF markers. 


\section{AGRICULTURAL AND FOOD SCIENCE}

\section{Results \\ AMF root colonization}

Among the mycorrhizal crops, the highest colonization percentages were observed in reed canary-grass (77\%) followed by flax (52\%) and caraway $(42 \%)$, while the lowest colonization was observed in timothy (9\%) and barley (13\%). The non-mycorrhizal crops showed no or extremely low (dyer's woad $0.6 \%$ ) root colonization. Notable is that quinoa, belonging to the mostly non-mycorrhizal Chenopodiaceafamily, had moderate levels (19\%) of colonization (Fig. 1.)

Fig. 1. AMF colonization in field collected root samples of ten crops with varying degrees of mycotrophy. Roots were collected at ripening time of crops in 2005. The dots represent means and the lines the standard deviation of means. $\mathrm{N}=9$. RCG $=$ Reed canary-grass.

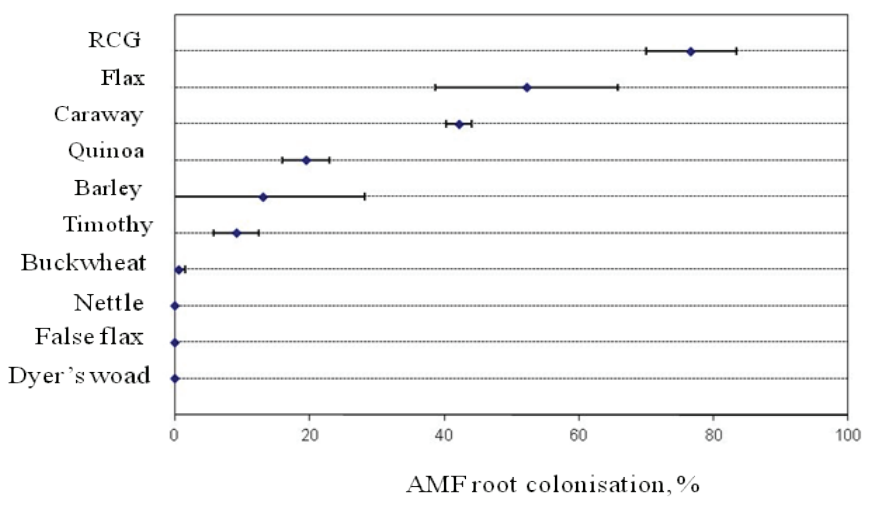

\section{AMF markers in the soil}

In bulk soil, crops affected significantly $(p<0.001)$ the MPN numbers of infective AMF propagules, the NLFA

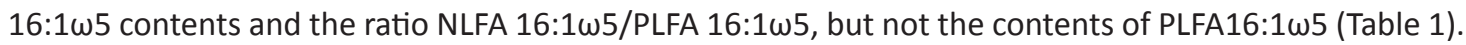
In rhizosphere soil, crops had a significant effect on all measured fatty acid properties (Table 1 ).

Table 1. Statistical test results for the main effect of crop on mycorrhizal markers and general microbial biomass indicators in bulk and rhizosphere soil. MPN = Most probable number, PLFA = Phospholipid fatty acid, NLFA = Neutral lipid fatty acid, PLFAtot $=$ Total amount of phospholipid fatty acids.

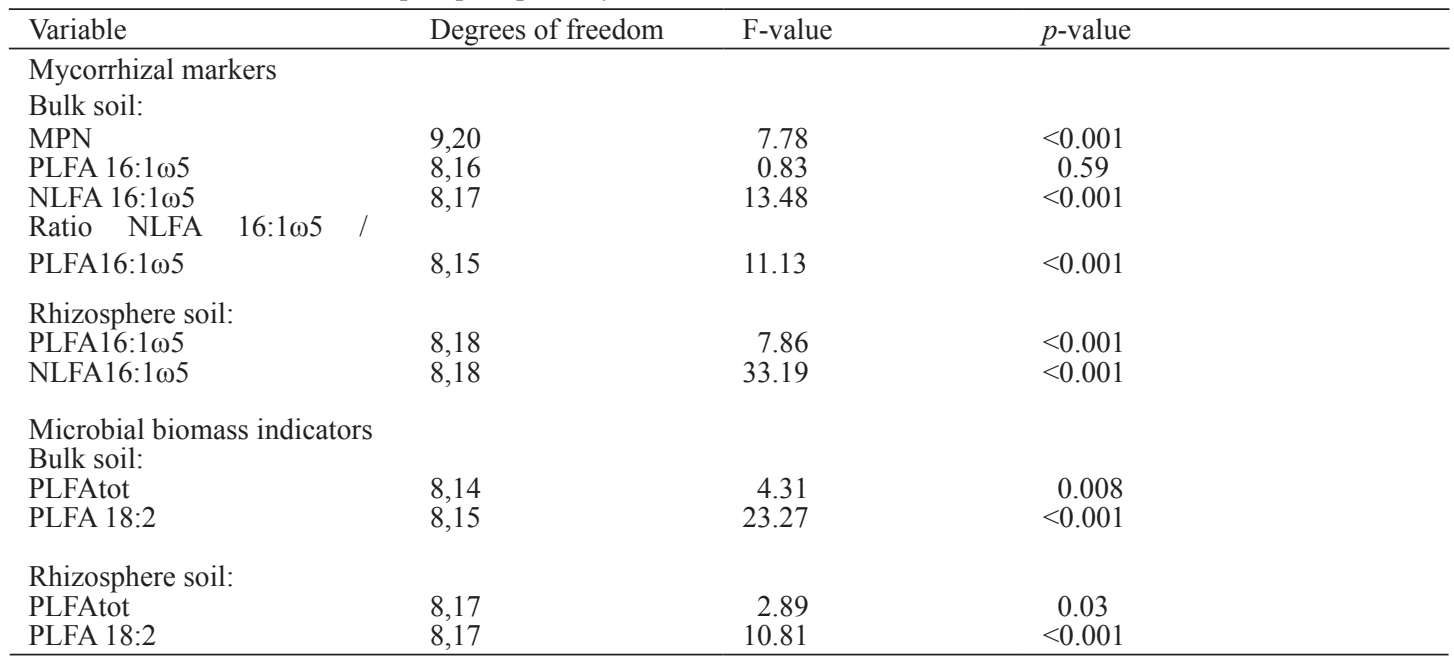




\section{AGRICULTURAL AND FOOD SCIENCE}

M. Vestberg et al. (2012) 21: 12-27

\section{MPN}

Estimated means of MPN propagules were significantly higher $(p=0.0015)$ in reed canary-grass (257 AMF propagules $100 \mathrm{~g}^{-1}$ soil) than in barley (68 AMF propagules $100 \mathrm{~g}^{-1} \mathrm{soil}$ ). Soil from the non-mycorrhizal crops buckwheat, false flax and dyer's woad had significantly lower levels of AMF propagules than barley. In contrast to the relatively high AMF root colonization, the estimated mean AMF propagule numbers from flax soil was only 36 . This value was at the same level as observed in the non-mycorrhizal crops (Fig. 2A).

A

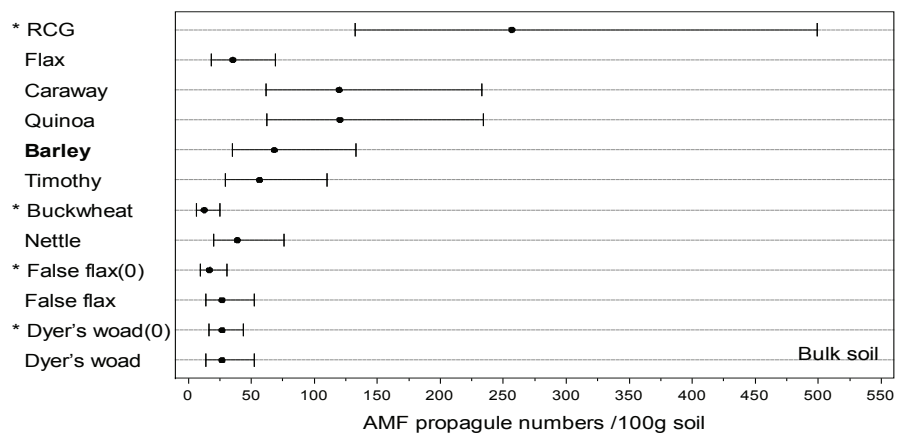

Fig. 2A. Effect of crops on the most probable numbers (MPN) of infective AMF propagules in bulk soil. Samples were collected at ripening time of crops in 2005. Statistically significant differences compared to barley are marked with an asterisk $(\mathrm{p}<0.05)$. The dots represent the estimated (model based, back transformed) mean and the lines represent the $95 \%$ confidence intervals for means. $\mathrm{N}=3$. In the MPN analysis, the results for false flax and dyer's woad are presented for the whole data and after removing one outlier (denoted by (0)) in both crops.

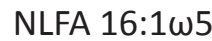

Crop had a strong impact on NLFA 16:1 $\omega 5$ levels both in bulk and rhizosphere soil (Fig. 2B). In bulk soil, the highest NLFA 16:1 $1 \omega 5$ levels were observed in soil from caraway $\left(46.23 \mathrm{nmol} \mathrm{g}^{-1}\right.$ soil) and reed canarygrass ( $46.13 \mathrm{nmol} \mathrm{g}^{-1}$ soil). These levels differed significantly ( $p=0.04$ for both crops) from the amount of

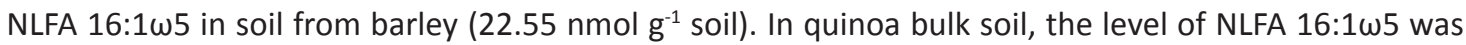
approximately the same as in barley, while the rest of the crops had significantly lower levels of NLFA 16:1 $\omega 5$ than barley (Fig. 2B). In rhizosphere soil, the NLFA 16:1 $\omega 5$ analysis yielded similar results as the analysis of bulk soil: rhizosphere soil from reed canary-grass, caraway and quinoa had significantly elevated levels of NLFA 16:1 $\omega 5$ compared with barley $(p<0.0001, p=0.0001$ and $p=0.0022$ for reed canary-grass, caraway and quinoa, respectively) (Fig. 2B).

B

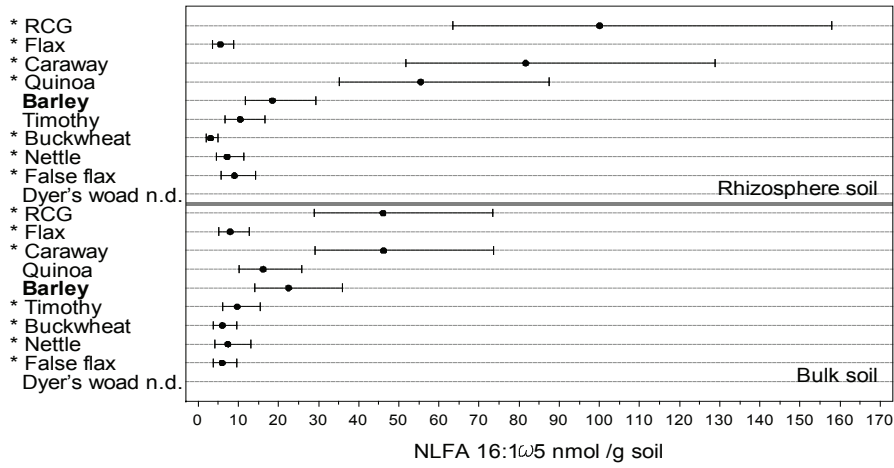

Fig. 2B. Effect of crops on the amounts of neutral lipid fatty acid (NLFA) $16: 1 \omega 5$ in rhizosphere and bulk soil. Samples were collected at ripening time of crops in 2005. Statistically significant differences compared to barley are marked with an asterisk $(p<0.05)$. The dots represent the estimated (model based, back transformed) mean and the lines represent the $95 \%$ confidence intervals for means. $\mathrm{N}=3$. 


\section{AGRICULTURAL AND FOOD SCIENCE}

M. Vestberg et al. (2012) 21: 12-27

\section{PLFA 16:1 $\omega 5$}

Estimated means of PLFA 16:1 $\omega 5$ in bulk soil varied little between crops being the highest $\left(6.39 \mathrm{nmol} \mathrm{g}^{-1}\right.$ soil) in reed canary-grass and the lowest $\left(4.79 \mathrm{nmol} \mathrm{g}^{-1}\right.$ soil) in nettle (Fig. $2 \mathrm{C}$ ). In the rhizosphere, the PLFA $16: 1 \omega 5$ levels were higher than in the bulk soil, irrespective of mycotrophy of the crop. The highest levels were measured in soil from reed canary-grass $\left(12.03 \mathrm{nmol} \mathrm{g}^{-1}\right.$ soil) and the lowest from flax $\left(6.87 \mathrm{nmol} \mathrm{g}^{-1}\right.$ soil) In comparison with barley, statistically significantly elevated PLFA levels were measured in rhizosphere soil from reed canary-grass $(p=0.025)$ and quinoa $(p=0.0494)$, while lower levels were measured in flax $(p=0.0031)$ and buckwheat $(p=0.0163)$.

C

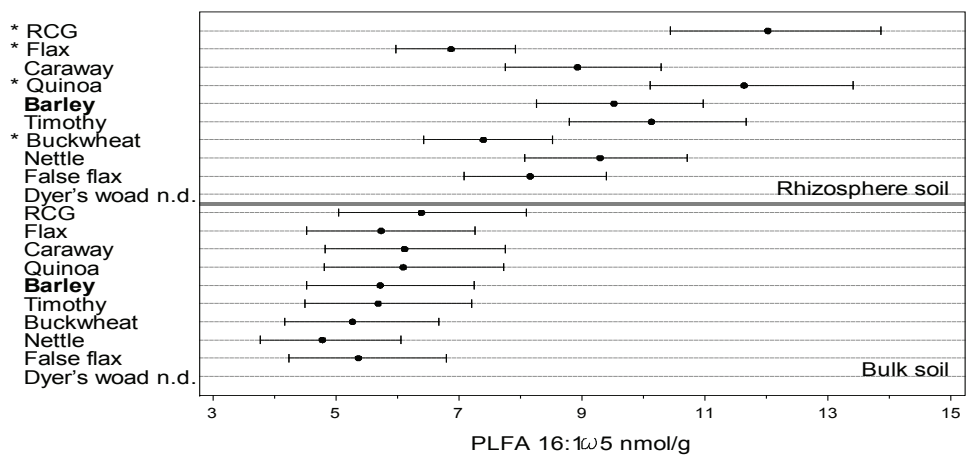

Fig. 2C. Effect of crops on the amounts of phospholipid fatty acid (PLFA) 16:1 15 in rhizosphere and bulk soil, and (D) the ratio NLFA $16: 1 \omega 5$ to PLFA 16:1 15 in rhizosphere and bulk soil. Samples were collected at ripening time of crops in 2005. Statistically significant differences compared to barley are marked with an asterisk $(\mathrm{p}<$ $0.05)$. The dots represent the estimated (model based, back transformed) mean and the lines represent the $95 \%$ confidence intervals for means. $\mathrm{N}=3$.

\section{Ratio NLFA/PLFA 16:1 $\omega 5$}

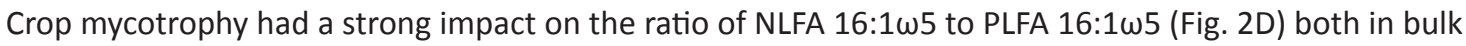
and in rhizosphere soil. In both cases, the highest ratios were observed with the mycotrophic crops caraway and reed canary-grass while values less than 1 were observed in the non-mycorrhizal buckwheat $(0.42)$ and nettle (0.78) and the mycorrhizal flax (0.81). The observed differences were mainly due to variations in the NLFA 16:1 $\omega 5$ concentrations.

D

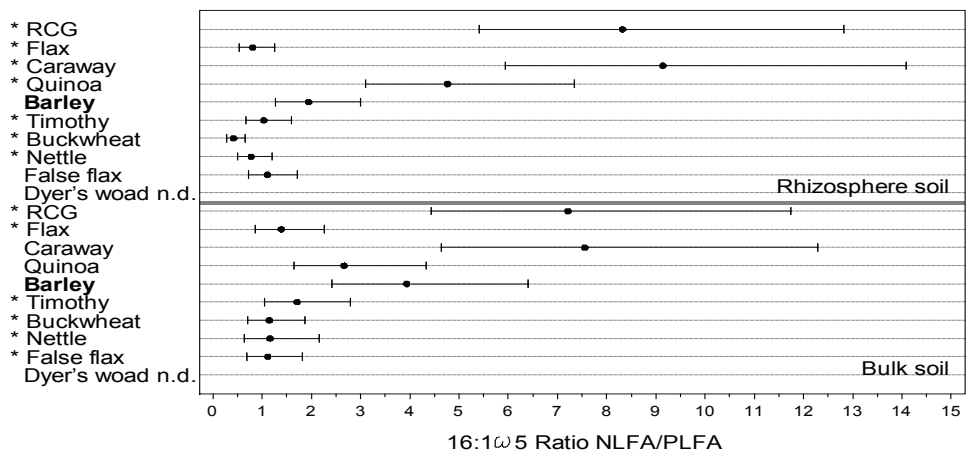

Fig. 2D. Effect of crops on the ratio NLFA $16: 1 \omega 5$ to PLFA $16: 1 \omega 5$ in rhizosphere and bulk soil. Samples were collected at ripening time of crops in 2005. Statistically significant differences com-pared to barley are marked with an asterisk ( $\mathrm{p}<$ 0.05 ). The dots represent the estimated (model based, back transformed) mean and the lines represent the $95 \%$ confidence intervals for means. $\mathrm{N}=3$. 


\section{AGRICULTURAL AND FOOD SCIENCE}

M. Vestberg et al. (2012) 21: 12-27

The relationships between mycorrhizal markers in rhizosphere and bulk soil are presented in Table 2 . NLFA 16:1 $\omega 5$ levels in rhizosphere and bulk soil correlated positively with each other $(r=0.86)$. High positive correlation ( $r=0.77$ ) was also observed between NLFA 16:1 $\omega 5$ and MPN numbers of AMF propagules in

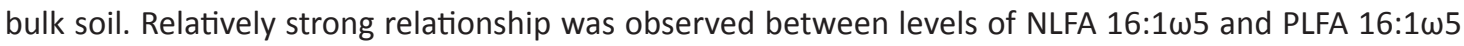
in rhizosphere soil ( $r=0.68)$, between MPN numbers of AMF propagules and PLFA 16:1 $\omega 5$ in rhizosphere soil ( $r=0.67)$ and between MPN numbers of AMF propagules and NLFA 16:1 $\omega 5$ in bulk soil $(r=0.66)$. The percentage of AM colonization of roots did not correlate with any other AMF markers.

Table 2. Correlations coefficients between log transformed mycorrhizal markers measured in rhizosphere and bulk soil and as AM colonization of roots. Data from a field experiment with 10 crops. Correlation coefficients higher than 0.6

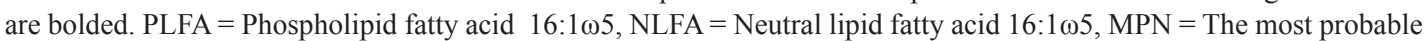
numbers of infective arbuscular mycorrhizal fungal propagules, $\mathrm{AM}=$ Arbuscular mycorrhizal, $\mathrm{n}=$ Number of samples.

\begin{tabular}{|c|c|c|c|c|c|c|}
\hline & \multicolumn{2}{|c|}{ Rhizosphere soil } & \multicolumn{3}{|c|}{ Bulk soil } & \multirow{2}{*}{$\begin{array}{l}\text { Root } \\
\mathrm{AM}^{1)} \\
\text { colonization }\end{array}$} \\
\hline & PLFA & NLFA & PLFA & NLFA & MPN & \\
\hline Rhizosphere soil, PLFA & & $\begin{array}{l}\mathbf{0 . 6 8} \\
(n=27)\end{array}$ & $\begin{array}{l}0.42 \\
(n=26)\end{array}$ & $\begin{array}{l}0.42 \\
(n=26)\end{array}$ & $\begin{array}{l}\mathbf{0 . 6 7} \\
(n=27)\end{array}$ & $\begin{array}{l}-0.15 \\
(n=18)\end{array}$ \\
\hline Rhizosphere soil, NLFA & & & $\begin{array}{l}0.45 \\
(n=26)\end{array}$ & $\begin{array}{l}\mathbf{0 . 8 6} \\
(n=26)\end{array}$ & $\begin{array}{l}\mathbf{0 . 7 7} \\
(n=27)\end{array}$ & $\begin{array}{l}0.32 \\
(n=18)\end{array}$ \\
\hline Bulk soil, PLFA & & & & $\begin{array}{l}0.40 \\
(n=26)\end{array}$ & $\begin{array}{l}0.40 \\
(n=26)\end{array}$ & $\begin{array}{l}0.45 \\
(n=18)\end{array}$ \\
\hline Bulk soil, NLFA & & & & & $\begin{array}{l}\mathbf{0 . 6 6} \\
(n=26)\end{array}$ & $\begin{array}{l}0.33 \\
(n=18)\end{array}$ \\
\hline Bulk soil, MPN & & & & & & $\begin{array}{l}0.38 \\
(n=19)\end{array}$ \\
\hline
\end{tabular}

Root, AM colonization

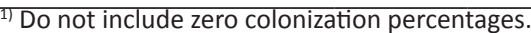

\section{Soil microbial biomass indicators}

Overall, the general microbial biomass indicator PLFAtot and the saprophytic fungal biomass signature fatty acid 18:2 were significantly influenced by crop species, both in bulk and in rhizosphere soil (Table 1).

The fungal biomass signature fatty acid PLFA 18:2 (Fig. 3A) was more variable than PLFAtot (Fig. 3B) across the crops. In the bulk soil, all crops except flax and false flax showed higher levels of PLFA 18:2 than barley ( $p=0.015, p=0.0001, p=0.0005, p<0.0001, p=0.0012, p<0.0001$ for reed canary-grass, quinoa, timothy, nettle, caraway and buckwheat, respectively). In the rhizosphere soil, the situation was somewhat similar. Compared with barley, the levels of PLFA 18:2 were higher in all crops except for reed canary-grass, flax and false flax ( $p=0.0007, p=0.0081, p=0.0002, p<0.0001, p=0.0003$ for quinoa, timothy, nettle, caraway and buckwheat, respectively; false flax statistically significantly higher than barley if an influential outlier was omitted).

The total soil microbial biomass indicator PLFAtot was less affected by crop species than the saprophytic fungal biomass indicator (Fig. 3B). Compared to barley, statistically significantly lower values were seen for false flax and flax ( $p=0.0325$ and $p=0.0238$, respectively). In the rhizosphere soil (Fig. 3B), 


\section{AGRICULTURAL AND FOOD SCIENCE}

M. Vestberg et al. (2012) 21: 12-27

the variation of PLFAtot values was higher than in the bulk soil. Statistically significant differences compared to barley were found for caraway and nettle, when omitting one outlier, or with caraway alone $(p$ $=0.0262$ ) when including all data.
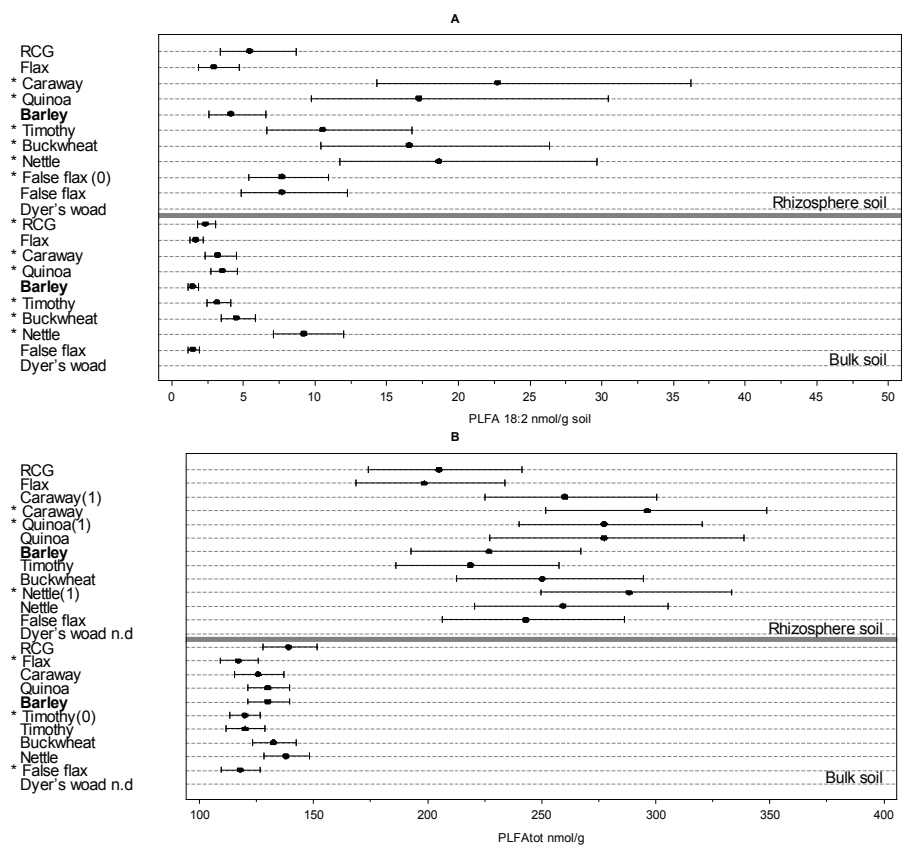

Fig. 3. Effect of crops on (A) saprophytic fungal biomass, indicated by signature fatty acid 18:2 (PLFA 18:2), and on (B) total microbial biomass, indicated by the total amount of PLFAs (PLFA-tot) in rhizosphere and bulk soil. Samples were collected at ripening time of crops in 2005. Statistically significant differences compared to barley are marked with an asterisk $(\mathrm{p}<0.05)$. The dots represent the estimated (model based, back transformed) mean and the lines represent the $95 \%$ confidence intervals for means. $\mathrm{N}=3$. In $\mathrm{A}$, false flax vs. false flax (0) indicates values for the whole data and after omitting an influential outlier in caraway. In B, timothy vs. timothy (0), caraway vs. caraway (1), quinoa vs. quinoa (1) and nettle vs. nettle (1) indicate values for the whole data and after omitting one influential outlier of quinoa in rhizosphere soil and one outlier of nettle in rhizosphere and bulk soil.

\section{Discussion}

The impact of host mycotrophy on arbuscular mycorrhizal fungal (AMF) markers was studied in a field experiment with ten crop species that varied considerably in terms of their growth pattern, annual vs. perennial status and degree of mycotrophy. Several of the crops, for example reed canary-grass, quinoa, dyer's woad, nettle and false flax, are not commonly cultivated in cold temperate areas. This study gives valuable novel information about the impacts of these crops on AMF traits and soil microbiology in general.

Host mycotrophy clearly affected quantitative mycorrhizal markers in the rhizosphere and the bulk soil. Two years of cropping with mycorrhizal crops resulted in higher levels of MPN propagule numbers and fatty acid contents in soil compared with two years of cropping with non-mycorrhizal crops. This result is in agreement with many studies in which various crops and crop rotations have affected AMF propagule numbers in soil (e.g. An et al. 1993, Troeh and Loynachan 2003, Vestberg et al. 2005). Soil from reed canary-grass had the highest levels of AMF colonization, MPN propagule numbers, and PLFA 16:1 $\omega 5$ and NLFA 16:1w5 contents. Root colonization in reed canary-grass of even $90 \%$ or more was observed also by Gryndler et al. (2008) in a study done on coal mine spoil banks in Czech Republic. Such high AMF root colonization in a C3 grass can be regarded as exceptional, because these grasses have fibrous and highly branched root systems and have been regarded as only weakly dependent on AMF for nutrient acquisition 


\section{AGRICULTURAL AND FOOD SCIENCE}

M. Vestberg et al. (2012) 21: 12-27

(Janos 1980). About $84 \%$ of grasses are estimated to form arbuscular mycorrhizae in their roots (Newman and Reddel 1987). Cool season C3 grasses in particular are believed to be only weakly dependent on mycorrhizal symbiosis, while the warm season C4 grasses with coarse root system are obligate mycotrophs (Hetrick et al. 1988, Hetrick et al. 1990, Anjum et al. 2006).

It has to be noted that quinoa, belonging to the mostly non-mycorrhizal Chenopodiaceae family, had moderate levels of AMF root colonization and also higher MPN values and elevated levels of PLFA 16:1 $\omega 5$ in rhizosphere soil and of NLFA 16:1 $\omega 5$ in both rhizosphere and bulk soil compared with the non-mycorrhizal crops. Quinoa is a rare crop and its mycorrhizal status has earlier been reported only in two studies that we know of. Schwab (1982) found this crop weakly mycorrhizal under altered physiological conditions following simazine treatment. In a recent study quinoa was found to be non-mycorrhizal (Urcelay et al. 2011). Our study suggests that quinoa grown under temperate climatic conditions may have clear mycotrophic traits.

Flax had relatively high root colonization but all other mycorrhizal markers were at the same level as in the non-mycorrhizal crops. The low MPN levels and low fatty acid levels in both rhizosphere and bulk soil under flax are very surprising because flax is known to be an AMF dependent crop (Thompson 1994, Thingstrup et al. 1998, Kahiluoto et al. 2001), at least at low to moderate levels of P in soil (Thingstrup et al. 1998). The P level in our soil was relatively low $\left(9.5 \mathrm{mg} \mathrm{kg}^{-1}\right.$ soil) which is a prerequisite for mycorrhizal development and function in crops. Therefore, the result is unexpected and in contrast to Olsson et al. (1999) who found high levels of AMF in a flax (linseed) soil by using fatty acid analyses. The latter study reported a ten times higher amount of extraradical mycelium in flax soil than the mycorrhizal biomass inside the roots, and that the extraradical mycelium of AMF constituted the largest fraction of the microbial biomass in soil. In our case, the very low levels of AMF markers in rhizosphere soil indicted very sparse, or no development of extradical mycelium around roots of flax.

In a field experiment, with normal crop specific agricultural practises, confounding effects of factors other than the host plant cannot be excluded. Herbicides used to control weeds in flax plots may be partly responsible for the phenomenon of low AMF levels in the flax soil. Herbicides can cause direct effects on mycorrhizal abundance in soil, but the effects are very variable and often species and dosage-dependent (Dehn et al. 1990). Many herbicides are not directly fungitoxic, but may affect biotrophic organisms like the AMF indirectly by altering host-plant functions (Garcia-Romera et al. 1988). In our study, weeds in plots of flax were controlled by foliar spraying with bentazon and MCPA. Negative impacts of bentazon on AMF were found in a greenhouse study performed by Bethlenfalvay et al. (1996) with the highly mycorrhiza dependent crops cocklebur and soybean. AMF root colonization of cocklebur was reduced by $43 \%$ along with drastical reductions in leaf dry weight and N, P and $\mathrm{K}$ concentrations. However, bentazon did not cause significant changes in soybean. Garcia-Romera and Ocampo (1988) found that MCPA affected AM fungi negatively not only through the plant but also directly.

Soil sampling took place during an extended period of time due to differences in plant physiological development and ripening. This could potentially have had an impact on the results. However, the results of PLFAtot (indicator of total microbial biomass) in the bulk soil were rather stable and not dependent on sampling date indicating that sampling time had only minor impact on the overall microbial community. We considered the plant growth stage to be more important than date for this study of highly diverse crops, since plant growth stage has been shown to be the most important factor determining rhizosphere fungal communty composition and functioning (Hannula et al. 2010). 


\section{AGRICULTURAL AND FOOD SCIENCE}

M. Vestberg et al. (2012) 21: 12-27

The signature fatty acid PLFA 18:2 (often further indicated as 18:2w6,9), has commonly been used as a general indicator for fungal biomass (Frostegård et al. 1993). Olsson (1999) stated the 18:2 to be a specific indicator for saprophytic fungal biomass. Our results confirm the findings of Olsson (1999), since the PLFA 18:2 values showed a very different pattern compared with the AMF fatty acid markers PLFA and NLFA 16:1 $\omega 5$. The AMF may often form the main part of fungal biomass in arable soil (Olsson et al. 1999), which further points to the conclusion that signature fatty acids $18: 2$ and $16: 1 \omega 5$ are indicators of separate fungal groups in soil.

AMF species dependent differences in fatty acid composition may be a problem when using fatty acid based methods in mixed AM fungal communities (Olsson 1999). For example, both Glomus and Scutellospora species have a high proportion of fatty acid 16:1 $\omega 5$, while the proportion of this fatty acid is low in Gigaspora species (Bentivenga and Morton 1996). Van Arle and Olsson (2003) found that Gl. intraradices partitioned most of its storage lipids and biomass to the intraradical mycelium, whereas $S$. calospora partitioned most to the extraradical mycelium. Such sources of variation are however unlikely to occur in agricultural soil with a long history of cultivation with mainly annual crops. In such soils, species of the genus Glomus are highly dominating, a fact that has been observed in Finnish studies of agricultural soil (Vestberg et al. 2005) and in studies done elsewhere (Oehl et al. 2003).

PLFA 16:1 $\omega 5$ has been shown to correlate closely with the AMF hyphal length in soil (Olsson et al. 1997). In this study, bulk soil values of PLFA 16:1 $\omega 5$ did not differ between plants in spite of high variation in AMF root colonization-\%. This suggests considerable level of background fatty acids from other microbes in such soil samples. The background level of PLFA 16:1 $\omega 5$ can vary between 30 and $60 \%$ of total PLFA 16:1 $\omega 5$ (Olsson 1999) being mainly due to bacteria even though other non-AMF fungi may contribute (Olsson 1999). PLFA 16:1 55 values in rhizosphere soil showed more crop based variation and, with the exception of caraway, the trend was close to the values of AMF propagule numbers (MPN-method) in bulk soil and the AMF indicator NLFA 16:1 $\omega 5$ values both in bulk and rhizosphere soil. This could indicate higher proportion of AMF originated PLFA 16:1 $\omega 5$ in rhizosphere soil compared to bulk soil. Similarities between our results of AMF propagule numbers and NLFA 16:1 $\omega 5$ values fit well to the findings of Olsson et al. (1997) that NLFA 16:1 $\omega 5$ correlated closely with the numbers of AMF spores in soil.

With the exception of PLFA 16:1 $\omega 5$ in bulk soil, all AMF marker methods differentiated relatively well the mycorrhizal crops from the non-mycorrhizal crops. The ratio of NLFA 16:1 $\omega 5$ to PLFA 16:1 $\omega 5$ in the extraradical mycelium has been shown to correlate positively with root AMF colonization (Olsson et al. 1997). In our study, the ratio followed closely the results of soil AMF propagule numbers and NLFA 16:1 $\omega 5$ values.

All methods used in this study have their advantages and drawbacks. The MPN method is very laborious and time consuming. It needs much greenhouse or growth room space and the results are available only after about six weeks. Compared with the MPN test, the signature fatty acid analyses are fast and a higher throughput can be achieved. However, the choice of signature fatty acid is crucial. In this study, separate sampling from bulk and rhizosphere soil showed clear rhizosphere effect on the microbial abundance (clearly higher PLFAtot values in rhizosphere soil than in bulk soil), but for AMF fatty acid indicators the difference was not that clear. Based on this, and after considering advantages and disadvantages of other methods used, the ratio of NLFA 16:1 $\omega 5$ to PLFA 16:1 $1 \omega 5$ from field bulk soil is an adequate method as an indicator of AMF propagule biomass in soil. 


\section{AGRICULTURAL AND FOOD SCIENCE}

M. Vestberg et al. (2012) 21: 12-27

\section{Conclusions}

Crop species had a significant impact on AMF infective propagule numbers measured by MPN, NLFA 16:1 $\omega 5$ levels in bulk and rhizosphere soil, and by PLFA 16:1 $\omega 5$ levels in rhizosphere soil but not in bulk soil. Reed canary-grass generally induced the highest levels of AMF markers. Also caraway induced elevated levels of several AMF markers. Quinoa, belonging to the usually non-mycorrhizal Chenopodiaceae family, showed moderate AMF root colonization and, compared with barley, also elevated levels of PLFA and NLFA 16:1 $\omega 5$ in the rhizosphere soil. Flax, normally a mycorrhiza dependent crop, was well colonised by AMF, but the levels of all other AMF markers were low and at the same levels as those observed in the non-mycorrhizal crops. It is hypothesized that this unexpected result may at least partly be due to the use of herbicides bentazon and MCPA.

Separate sampling from bulk and rhizosphere soil revealed clear rhizosphere effect on microbes in general (clearly higher PLFAtot values in rhizosphere soil than in bulk soil) and higher proportion of AMF originated PLFA 16:1 $\omega 5$ in rhizosphere soil compared to bulk soil. The level of NLFA 16:1 $\omega 5$ values in bulk and rhizosphere soils did not differ greatly. Based on this, and after considering advantages and disadvantages of other methods used, NLFA 16:1 $\omega 5$ and the ratio of NLFA 16:1 $\omega 5$ to PLFA 16:1 $\omega 5$ from field bulk soil are adequate methods as indicators of AMF propagule biomass in soil.

Host plant mycotrophy varied conciderably among special crops studied. It can be concluded that crop mycothrophy has a strong impact on soil AMF content, which is an important factor to consider when designing crop rotations in cereal based agriculture beneficial for soil quality.

\section{Acknowledgements}

Technical staff of MTT at Jokioinen and Laukaa is greatly acknowledged for their skilled assistance in soil samplings and analyses.

\section{References}

Altman, D.G. \& Bland, J.M. 1983, Measurement in medicine: the analysis of method comparison studies. The Statistician 32: 307-317.

An, Z.-Q., Hendrix, J.W., Hershman, D.E., Ferriss, R.S. \& Henson, G.T. 1993. The influence of crop rotataion and soil fumigation on a mycorrhizal fungal community associated with soybean. Mycorrhiza 3: 171-182.

Anjum, T., Javaid, A. \& Shah, M.B.M. 2006. Correlation between plant growth and arbuscular mycorrhizal colonization in some rainy season grasses. Pakistan Journal of Botany 38: 843-849.

Batten, K.M., Scow, K.M. \& Espeland, E.K. 2008. Soil microbial community associated with an invasive grass differentially impacts native plant performance. Microbial Ecology 55: 220-228.

Bentivenga, S.P. \& Morton, J.B. 1996. Congruence of fatty acid methyl ester profiles and morphological characters of arbuscular mycorrhizal fungi in the Gigasporaceae. Proceedings of the National Academy of Science USA. 93: 5659-5662.

Bethlenfalvay, G.J., Mihara, K.L., Schreiner, R.P. \& McDaniel, H. 1996. Mycorrhizae, biocides, and biocontrol. 1. Herbicide-mycorrhiza interactions in soybean and cocklebur treated with bentazon. Applied Soil Ecology 3: $197-204$.

Carvalho, L.M., Caçador, L. \& Martins-Loução 2001. Temporal and spatial variation of arbuscular mycorrhizas in salt marsh plants of the Tagus estuary (Portugal). Mycorrhiza 11: 303-309.

Dehn, B., Bodmer, M. \& Schüepp, H. 1990. Influence of herbicides on VA mycorrhizal propagation in soil. Symbiosis 9: 223-227.

Douds, D.D. \& Millner, P.D. 1999. Biodiversity of arbuscular mycorrhizal fungi in agroecosystems. Agriculture, Ecosystems \& Environment 74: 77-93. 


\section{AGRICULTURAL AND FOOD SCIENCE}

M. Vestberg et al. (2012) 21: 12-27

Evelin, H., Kapoor, R. \& Giri, B. 2009. Arbuscular mycorrhizal fungi in alleviation of salt stress: a review. Annals of Botany 104: 1263-1280.

Fisher, R.A. \& Yates, F. 1970. Statistical tables for biological, agricultural and medicinal research. $6^{\text {th }}$ Edition. Hafner Publ Comp, Davien.

Frostegård, Å, Tunlid, A. \& Bååth, E. 1993. Phospholipid fatty acid composition, biomass, and activity of microbial communities from two soil types experimentally exposed to different heavy metals. Applied and Environmental Microbiology 59: 3605-3617.

Gadkar, V., David-Schwarz. R., Kunik, T. \& Kapulnik, Y. 2001. Arbuscular mycorrhizal fungal colonisation. Factors involved in host recognition. Plant Physiology 127: 1493-1499.

Garcia-Romera, I. \& Ocampo, J.A. 1988. Effect of the herbicide MCPA on VA mycorrhizal infection and growth of Pisum sativum. Zeitschrift für Pflanzenernährung und Bodenkunde 151: 225-228.

Gerdemann. J.W. \& Nicolson, T.H. 1963. Spores of mycorrhizal Endogone species extracted from soil by wet sieving and decanting. Transactions of the British Mycological Society 46: 235-244.

Grace, C. \& Stribley, D. 1991. A safer procedure for routine staining of vesicular arbuscular mycorrhizal fungi. Mycological Research 95: 1160-1162.

Graham, J.H., Hodge, N.C. \& Morton, J.B. 1995. Fatty acid methyl ester profiles for characterization of Glomalean fungi and their endomycorrhizae. Applied and Environmental Microbiology 61: 58-64.

Gryndler, M., Sudová, R., Püschel, D., Rydlová, J., Janousková, M. \& Vosátka, M. 2008. Cultivation of high-biomass crops on coal mine spoil banks: Can microbial inoculation compensate for high doses of organic matter? Bioresource Techology 99: 6391-6399.

Hakala, K., Keskitalo, M., Eriksson, C. \& Pitkänen, T. 2009. Nutrient uptake and biomass accumulation for eleven different crops. Agricultural and Food Science 18: 366-387.

Hannula, S.E, de Boer, W. \& van Veen, J.A. 2010. In situ dynamics of soil fungal communities under different genotypes of potato, including a genetically modified cultivar. Soil Biology and Biochemistry 42: 2211-2223.

Harinikumar, K.M. \& Bagyaraj, D. 1988. Effect of crop rotation on native vesicular-arbuscular mycorrhizae in soil. Plant and Soil 110: 77-80.

Harley, J.L., Harley, E.L. 1987. A check list of mycorrhiza in the British flora. New Phytologist 105 (Suppl.): 1-102 .

Hetrick, B.A.D., Kitt, D.G. \& Wilson, G.W.T. 1988. Mycorrhizal dependency and growth habit of warm season and cool season tall grass prairie plants. Canadian Journal of Botany 66: 1376-1380.

Hetrick, B.A.D., Wilson, G.W.T. \& Todd, T.C. 1990. Differential response of $\mathrm{C}_{3}$ and $\mathrm{C}_{4}$ grasses to mycorrhizal symbiosis, P. fertilization, and soil microorganisms. Canadian Journal of Botany 68: 461-467.

Janos, D.P. 1980. Mycorrhizae influence tropical succession. Biotropica 12: 56-64.

Johansen, A., Finlay, R.D. \& Olsson, P.A. 1996. Nitrogen metabolism of external hyphae of the arbuscular mycorrhizal fungus Glomus intraradices. New Phytologist 133: 705-512.

Kahiluoto, H., Ketoja, E., Vestberg, M. \& Saarela, I. 2001. Promotion of AM utilization through reduced P fertilization 2. Field studies. Plant and Soil 231: 65-79.

Karasawa, T., Kasahara, Y. \& Takebe, M. 2001. Variable response of growth and arbuscular mycorrhizal colonization of maize plants to preceding crops in various types of soils. Biology and Fertility of Soils 33: 286-293.

Karlen, D.L., Varvel, G.E., Bullock, D.G. \& Cruse, R.M. 1994. Crop rotations for the $21^{\text {st }}$ century. Advances in Agronomy 53: 1-45.

Kenward, M.G. \& Roger, J.H., 1997. Small sample inference for fixed effects from restricted maximum likelihood. Biometrics 53: 983-997.

Larsen, J., Olsson, P.A. \& Jakobsen, I. 1998. Mycelial interactions between the arbuscular mycorrhizal fungus Glomus intraradices and the saprophytic fungus Fusarium culmorum in root-free soil studied by the use of fatty acid signatures. Mycological Research 102: 1491-1496.

Littell R.C., Milliken G.A., Stroup W.W. \& Wolfinger R.D. 1996. SAS System for Mixed Models. Cary, NC: SAS Institue Inc. $633 \mathrm{p}$.

McGee, P.A., Torrisi, V. \& Pattinson, G.S. 1999. The relationship between density of Glomus mossae propagules and the initiation and spread of arbuscular mycorrhiza in cotton roots. Mycorrhiza 9: 221-225. 


\section{AGRICULTURAL AND FOOD SCIENCE}

M. Vestberg et al. (2012) 21: 12-27

Newman, E. \& Reddell, P. 1987. The distribution of mycorrhizas among families of vascular plants. New Phytologist 106: 745-751.

Oehl, F., Sieverding, E., Ineichen, K., Mäder, P., Boller, T. \& Wiemken, A. 2003. Impact of land use intensity on the species diversity of arbuscular mycorrhizal fungi in agroecosystems in Central Europe. Applied and Environmental Microbiology 69: 2816-2824.

Oehl, F., Sieverding, E., Mäder, P., Dubois, D., Ineichen, K., Boller, T. \& Wiemken, A. 2004. Impact of long-term conventional and organic farming on the diversity of arbuscular mycorrhizal fungi. Oecologia 138: 574-583.

Olsson, P.A. 1999. Signature fatty acids provide tools for determination of the distribution and interactions of mycorrhizal fungi in soil. MiniReview. FEMS Microbiology Ecology 29: 303-310.

Olsson, P.A., Bååth, E. \& Jakobsen, I. 1997. Phosphorus effects on the mycelium and storage structures of an arbuscular mycorrhizal fungus as studied in the soil and roots by analysis of fatty acid signatures. Applied and Environmental Microbiology 63: 3531-3538.

Olsson, P.A. \& Johansen, A. 2000. Lipid and fatty acid composition of hyphae and spores of arbuscular mycorrhizal fungi at different growth stages. Mycological Research 104: 429-434.

Olsson. P.A., Thingstrup, I., Jakobsen, I. \& Bååth, E. 1999. Estimation of the biomass of arbuscular mycorrhizal fungi in a linseed field. Soil Biology and Biochemistry 31: 1879-1887.

Pendleton, R.L. \& Smith, B.N. 1983. Vesicular-arbuscular mycorrhizae of weedy and colonizer plant species at disturbed sites in Utah. Oecologia 59: 296-301.

Porter, W.M. 1979. The 'most probable number' method for enumerating infective propagules of vesicular arbuscular mycorrhizal fungi in soil. Australian Journal of Soil Research 17: 515-519.

Pozo, M.J., Jung, S.J., López-Ráez, J.A. \& Azcón-Aguilar, C. 2010. Impact of arbuscular mycorrhizal symbiosis on plant response to abiotic stress: the role of plant defence mechanisms. In: Koltai, H. \& Kapulnik, Y. (eds.). Arbuscular Mycorrhizas: Physiology and Function, Springer Science+Business Media B.V. p. 193-207.

Rillig, M.C. 2004. Arbuscular mycorrhizae, glomalin, and soil aggregation. Canadian Journal of Soil Science 84: $355-363$.

Schmalenberger, A. \& Tebbe, C.C. 2003. Bacterial diversity in maize rhizospheres: conclusions on the use of genetic profiles based on PCR-amplified partial small subunit rRNA genes in ecological studies. Molecular Ecology 12: $251-261$.

Schwab, S.M., Johnson, E.L.V. \& Menge, J.A. 1982. Influence of simatzine on formation of vesicular-arbuscular mycorrhizae in Chenopodium quinona Willd. Plant and Soil 64: 283-287.

Sieverding, E. 1991. Vesicular-arbuscular mycorrhiza management in tropical agrosystems. Eschborn: Deutsche Gesellshaft für Technische Zusammenarbeit (GTZ) Gmbh, Technical Cooperation Federal Republic of Germany. 371 p.

Smith, D.E. \& Read, D.J. 1997. Mycorrhizal Symbiosis. London: Academic Press. 605 p.

Stoeck, T., Kröncke, I., Duineveld, G.C.A. \& Palojärvi, A. 2002. Phospholipid fatty acid profiles at depositional and nondepositional sites in the North sea. Marine Ecology Progress Series 241: 57-71.

Thingstrup, I., Rubæk, Sibbesen, E. \& Jakobsen, I. 1998. Flax (Linum usitatissimum) depends on arbuscular mycorrhizal fungi for growth and P uptake at intermediate but not high soil P levels in the field. Plant and Soil 203: 37-46.

Thompson, J.P. 1994. Inoculation with vesicular-arbuscular mycorrhizal fungi from cropped soil overcomes long-fallow disorder of linseed (Linum usitatissimum L.) by improving P and Zn uptake. Soil Biology and Biochemistry 26: 1133-1143.

Troech, Z.I. \& Loynachan, T.E. 2003. Endomycorrhizal fungal survival in continuous corn, soybean and fallow. Agronomy Journal 95: 224-230.

Tukey, J.W. 1977. Exploratory Data Analysis. Reading, MA: Addison-Wesley. 688 p.

Urcelay, C., Acho, J. \& Joffre, R. 2011. Fungal root symbionts and their relationship with fine root proportion in native plants from the Bolivian highlands above 3,700 elevation. Mycorrhiza 21: 323-330.

Van Arle, I.M. \& Olsson, P.A. 2003. Fungal lipid accumulation and development of mycelial structures by two arbuscular mycorrhizal fungi. Applied and Environmental Microbiology 69: 6762-6767.

Vestberg, M., Saari, K., Kukkonen, S. \& Hurme, T. 2005. Mycotrophy of crops in rotation and soil amendment with peat influence the abundance and effectiveness of indigenous arbuscular mycorrhizal fungi in field soil. Mycorrhiza 15: 447-458.

Vierheilig, H., Iseli, B., Alt, M. Raikhel, N., Wiemken, A. \& Boller, T. 1996. Resistance of Urtica dioica to mycorrhizal colonization: a possible involvement of Urtica dioica agglutinin. Plant and Soil 183: 131-136. 


\section{AGRICULTURAL AND FOOD SCIENCE}

M. Vestberg et al. (2012) 21: 12-27

Vuorinen J. \& Mäkitie, O. 1955. The method of soil testing in use in Finland. Agrogeological Publications 63:1-44.

Wang, Y.Y., Vestberg, M., Walker, C., Hurme, T. Zhang, X. \& Lindström, K. 2008. Diversity and infectivity of arbuscular mycorrhizal fungi in agricultural soils of the Sichuan Province of mainland China. Mycorrhiza 18: 59-68.

Wilson, J.M. \& Trinick, M.J. 1982. Factors affecting the estimation of numbers of infective propagules of vesicular arbuscular mycorrhizal fungi. Australian Journal of Soil Research 21: 73-81.

Wright, S.F. \& Upadhyaya, A. 1996. Extraction of an abundant and unusual protein from soil and comparison with hyphal protein of arbuscular mycorrhizal fungi. Soil Science 161: 575-586. 